\title{
Speed Adaptive Sliding Mode Control with an Extended State Observer for Permanent Magnet Synchronous Motor
}

\author{
Peipei Xia, ${ }^{1,2}$ Yongting Deng ${ }^{(D)}{ }^{1}$ Zhiqian Wang, ${ }^{1}$ and Hongwen $\mathrm{Li}^{1}$ \\ ${ }^{1}$ Changchun Institute of Optics, Fine Mechanics and Physics, Chinese Academy of Sciences, Changchun 130033, China \\ ${ }^{2}$ University of Chinese Academy of Sciences, Beijing 100049, China \\ Correspondence should be addressed to Yongting Deng; dyt0612@163.com
}

Received 6 September 2017; Revised 29 December 2017; Accepted 4 January 2018; Published 31 January 2018

Academic Editor: Michele Betti

Copyright (c) 2018 Peipei Xia et al. This is an open access article distributed under the Creative Commons Attribution License, which permits unrestricted use, distribution, and reproduction in any medium, provided the original work is properly cited.

\begin{abstract}
The sliding mode control (SMC) strategy is employed to a permanent magnet synchronous motor (PMSM) vector control system in this study to improve system robustness against parameter variations and load disturbance. To decrease the intrinsic chattering behavior of SMC, a speed SMC with an adaptive law and an extended state observer (ESO) is proposed. In this method, based on the Lyapunov stability theorem, adaptive estimation laws are deduced to estimate uncertainties of a PMSM caused by parameter variations and unmodeled dynamics. Online estimated uncertainties can be used to eliminate the effect caused by the real uncertainties. In addition, an ESO is applied to observe the load disturbance in real time. The load disturbance observed value is then utilized to the output side of the speed adaptive SMC controller as feed-forward compensation. Both the simulation and experiment results demonstrate that the proposed approach effectively alleviates system chattering and enhances system robustness against uncertainty and load disturbance.
\end{abstract}

\section{Introduction}

With the development of power electronics, microprocessors, and digital signal processors, the PMSM, which possess the characteristics of high efficiency, superior power density, a high torque to inertia ratio, high reliability, and easy maintenance [1], is now used extensively in various industrial applications. It is well known that the PMSM has nonlinear characteristics and strongly coupled problem. Therefore filedorientation control in a PMSM system is usually employed; this technique makes the PMSM have the same torque control performance as a DC motor [2].

In past, a proportional-integral (PI) control technique based on the field-orientation control is widely used due to their simple implementation. However, in practical, the system will face unavoidable uncertainties caused by parameter variations, unstructured dynamics, and load disturbance, which makes it very difficult for PI controller to achieve high-precision control requirements [3]. Thus, to obtain high performance and system robustness, advanced motor controllers are necessary.
Recently, with the rapid progress in modern control theories, many researchers have contributed to the development of nonlinear control methods for the PMSM, for example, adaptive control $[4,5]$, robust control $[6,7]$, intelligent control $[8,9]$, model predictive control $[10]$, and slidingmode control [11, 12].

Among these nonlinear control methods, SMC method has been widely applied for its advantages of simple implementation, strong robustness, and quick response. In real applications, the robustness of SMC can only be guaranteed by the large control gain; however, this aggravates the inherent chattering of SMC, which substantially reduces system performance. In order to avoid the trade-off between sliding-mode chattering and robustness to uncertainties, an SMC method with the simple uncertainties estimation terms was developed [13], which estimates uncertainties of a PMSM caused by parameter variations and unmodeled dynamics online, the estimated uncertainties can be used to eliminate the effect caused by the real uncertainties and thus improves system dynamic response and attains high static accuracy. Simultaneously, the system stability and robustness 


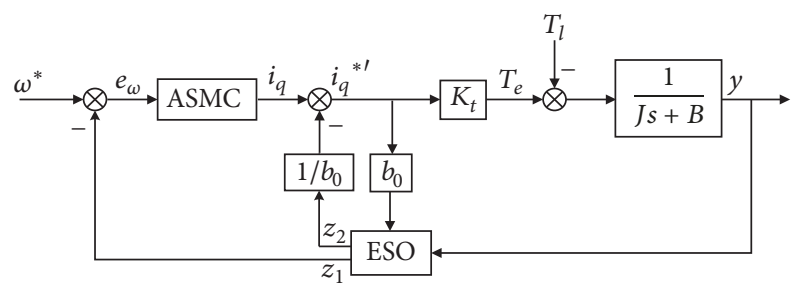

FIGURE 1: Schematic diagram of the PMSM speed regulation system based on ASMC and an ESO.

TABLE 1: Specifications of the PMSM.

\begin{tabular}{lc}
\hline Parameters & Value \\
\hline Phase induction $L$ & $30.08 \mathrm{mH}$ \\
Stator resistance $R$ & $15.42 \Omega$ \\
Torque constant $K$ & $0.41 \mathrm{~N} \cdot \mathrm{m} / \mathrm{A}$ \\
Pole pairs $p$ & 4 \\
Rotor inertia $J$ & $0.138 \mathrm{~kg} \cdot \mathrm{cm}^{2}$ \\
Rated power & $200 \mathrm{w}$ \\
Rated speed & $3000 \mathrm{r} / \mathrm{min}$ \\
\hline
\end{tabular}

to uncertainties can be guaranteed. Similarly, in [14], an SMC method with an extended state observer was proposed. In this approach, the load disturbance is observed by the ESO in real time, the load disturbance observed value is then used to the output of the speed controller as feed-forward compensation. This enhances system robustness under load disturbance and effectively alleviates system chattering.

Compared with the above literatures, the proposed SMC combines with the uncertainties estimation terms and an ESO for speed control in a PMSM. The best advantages are that the uncertainties and load disturbance can be estimated online and used effectively to compensate the controller. Simultaneously, the system stability and robustness can be guaranteed.

This paper is organized as follows: in Section 2, the dynamic model of the PMSM is described. Sections 3 and 4 design the ASMC and ESO for speed control of a PMSM in detail, respectively. Section 5 gives the results of simulation and experiment to demonstrate the effectiveness of the proposed control scheme. In Section 6, the paper is concluded.

\section{Dynamic Model of PMSM}

Taking the rotor coordinates ( $d-q$ axis) of the motor as reference coordinates, the voltage equations can be expressed as follows [4]:

$$
\begin{aligned}
& u_{d}=R_{s} i_{d}-\omega L_{q} i_{q}+L_{d} \frac{d i_{d}}{d t}, \\
& u_{q}=R_{s} i_{q}+\omega L_{d} i_{d}+\omega \psi_{a}+L_{q} \frac{d i_{q}}{d t},
\end{aligned}
$$

where $u_{d}$ and $u_{q}$ are the direct axis and quadrature axis stator voltages, $R_{s}$ is the stator resistance of motor, $i_{d}$ and $i_{q}$ are the direct axis and quadrature axis stator currents, $\omega$ is the mechanical angular speed of the rotor, $L_{q}=L_{d}=L$ are the stator inductances for the PMSM, and $\psi_{a}$ denotes the flux linkages of the permanent magnet rotor.

The electromagnetic torque equation can be expressed by

$$
T_{e}=\frac{3}{2} p\left(\psi_{a} i_{q}+\left(L_{d}-L_{q}\right) i_{d} i_{q}\right)
$$

where $T_{e}$ is electromagnetic torque developed by the motor and $p$ is the number of pole pairs.

Using the field-oriented PMSM control approach, the direct axis current $i_{d}$ is maintained at zero to maximize the output torque. Thus, (2) can be rewritten as

$$
T_{e}=\frac{3}{2} p \psi_{a} i_{q}=K_{t} i_{q}
$$

where $K_{t}$ is defined as the torque constant:

$$
K_{t}=\frac{3}{2} p \psi_{a}
$$

The mechanical equation can be expressed as

$$
J \frac{d \omega}{d t}=T_{e}-B \omega-T_{l},
$$

where $J$ is the moment of inertia, $T_{l}$ is the applied external load torque, and $B$ is the viscous friction coefficient.

PI algorithms are used in each of the two current loops. We construct the model using the speed control law, which is a straightforward combination of the ASMC feedback with the ESO-based feed-forward compensation to ensure that the PMSM control system achieves a better performance in the presence of uncertainties and load disturbances.

\section{Design of Speed ASMC}

(A) Speed Control Model. Consider the parameter variations of the system, defined as

$$
\begin{aligned}
& a^{\prime}=a+\Delta a, \\
& b^{\prime}=b+\Delta b, \\
& c^{\prime}=c+\Delta c,
\end{aligned}
$$

where $a=B / J, b=K_{t} / J, \quad c=1 / J$ are the nominal parts and $\Delta a=\Delta(B / J), \Delta b=\Delta\left(K_{t} / J\right), \Delta c=\Delta(1 / J)$ are the parameter variations of $a^{\prime}, b^{\prime}, c^{\prime}$, respectively. Therefore, (5) can be rewritten as

$$
\dot{\omega}=-a^{\prime} \omega+b^{\prime} i_{q}-c^{\prime} T_{l} .
$$

It is well known that parameter variations lead to the existence of model uncertainties. Model uncertainties can be constructed as follows:

$$
f=\Delta a \omega-\Delta b i_{q}+\Delta c T_{l}-\varepsilon
$$

where $\varepsilon$ is other uncertainties due to unmodeled dynamics. In addition, assume that $|\Delta a| \leq a_{1},|\Delta b| \leq b_{1},|\Delta c| \leq c_{1},|\varepsilon| \leq$ $d_{1}$, where $a_{1}, b_{1}, c_{1}$, and $d_{1}$ are upper bounds, respectively. 


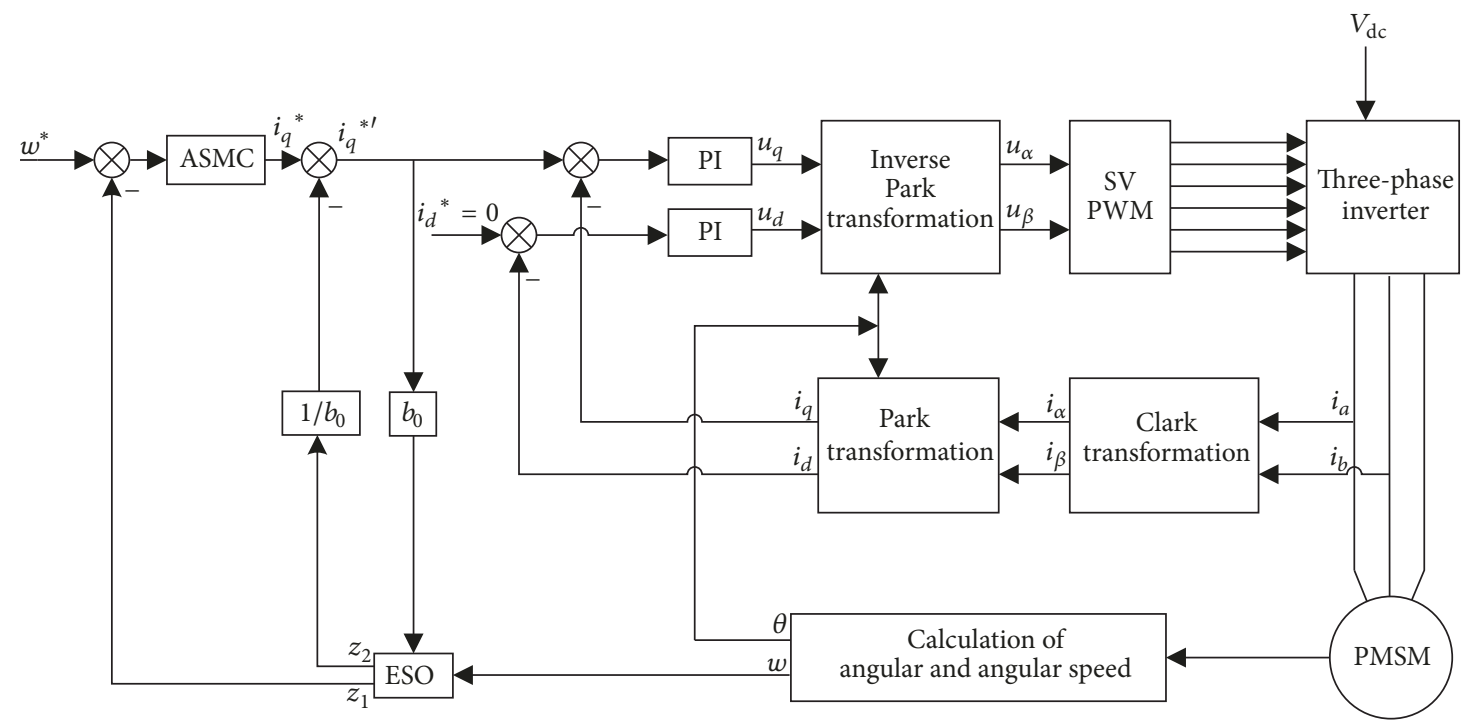

FIGURE 2: Schematic diagram of the PMSM speed servo system based on ASMC + ESO.
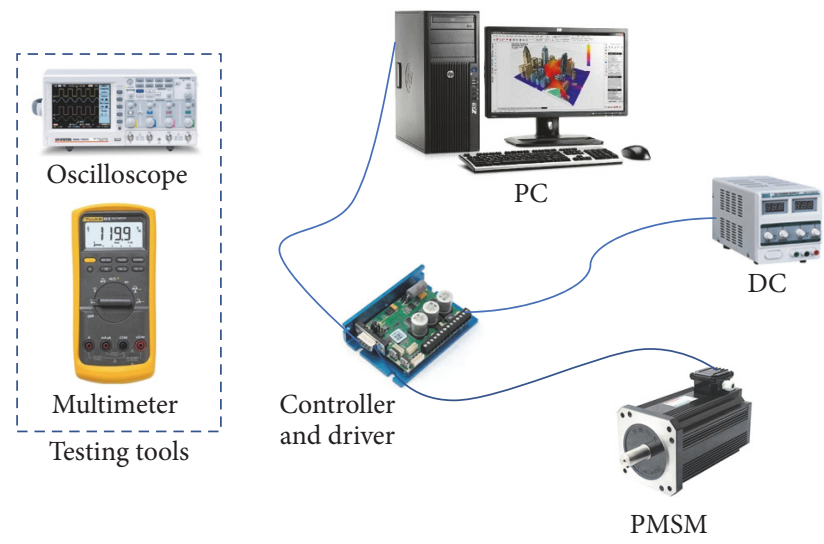

FIGURE 3: Photograph of the experimental platform.

Substituting (8) into (7) gives

$$
\dot{\omega}=-\frac{B}{J} \omega+\frac{K_{t}}{J} i_{q}-\frac{1}{J} T_{l}-f .
$$

In the speed control system, the state variable is speed error $e_{\omega}$, and we define the tracking error between reference and actual speed as

$$
e_{\omega}=\omega^{*}-\omega
$$

where $\omega^{*}$ is the reference speed.

Differentiating error equation (10), it can be rearranged in the form of

$$
\dot{e}_{\omega}=\dot{\omega}^{*}+A e_{\omega}+B^{\prime} i_{q}+D+f,
$$

where $A=-B / J, B^{\prime}=-K_{t} / J$, and $D=(1 / J) T_{l}+(B / J) \omega^{*}$ represents the disturbance item.

(B) Sliding Surface. An efficient solution for counteracting the parameter variations is the integral-type sliding-mode surface [15], which can eliminate the static system errors. In contrast to the differentiable-type sliding-mode surface, the differentiation of $e_{\omega}$ is unnecessary. Hence, the noises caused by the differentiation signal of $e_{\omega}$ can be avoided, which improves the stability of the system [16]. The integral sliding-mode surface with respect to the speed error signal $e_{\omega}$ is utilized as follows:

$$
s=e_{\omega}+k_{1} \int_{0}^{t} e_{\omega}(\tau) d \tau
$$

where $k_{1}>0$ is the integral coefficient of the sliding surface. As long as an appropriate control law is available, then the sliding mode will be obtained in finite time. In the sliding mode, the error dynamics will be

$$
\begin{aligned}
& s=0, \\
& \dot{s}=\dot{e}_{\omega}+k_{1} e_{\omega}=0 .
\end{aligned}
$$

The choice of $k_{1}$ decides the decaying rate of the speed tracking error. Hence, the error dynamics in the sliding mode can be assigned as stable.

The next step in SMC design is to derive a suitable control law such that $s$ satisfies the following sliding-mode accessibility condition:

$$
s \dot{s}<0 .
$$

When the sliding-mode accessibility condition is guaranteed, $s$ will approach zero in finite time and is sustained thereafter; that is, the sliding mode exists and is reachable.

(C) Reaching Law. According to the sliding variable structure principle, the sliding-mode accessibility condition in (14) can only ensure that the system state, which can be located anywhere in the state space, can arrive at the switching surface in a finite time; the state trajectories have no restrictions [17]. However, the integral sliding surface always leads to severe 


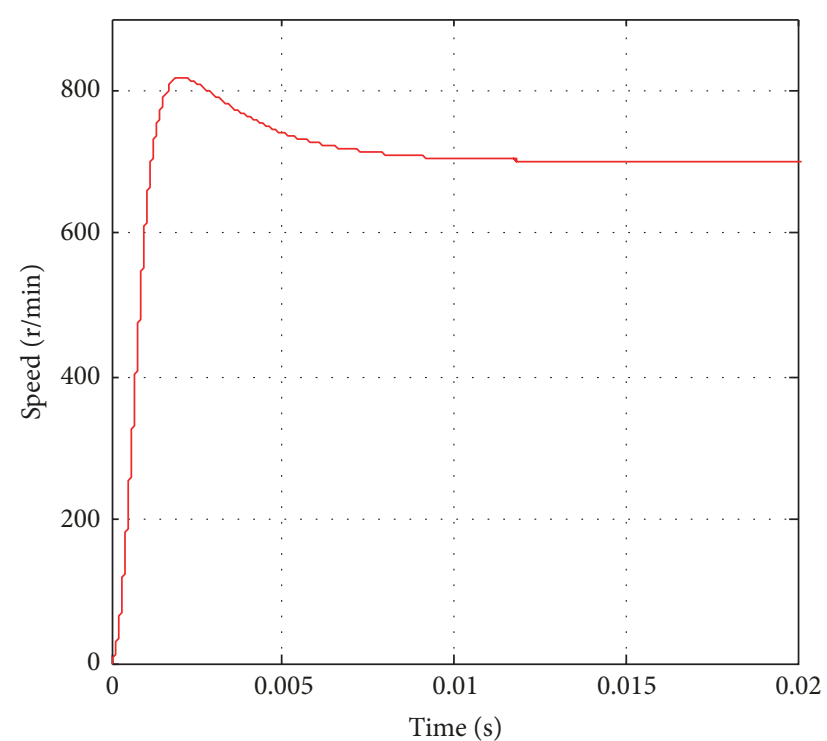

(a)

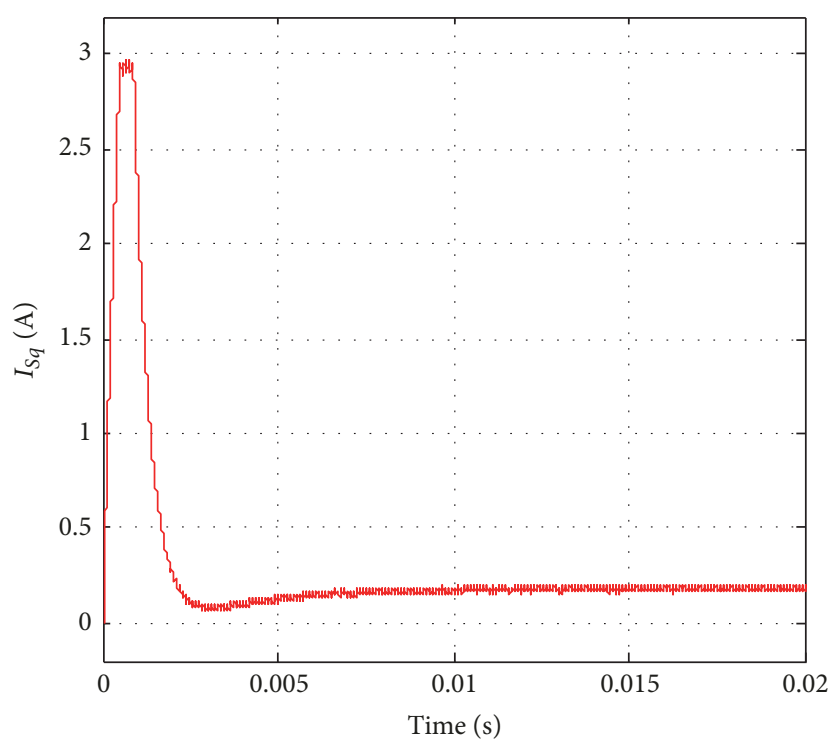

(b)

FIgURE 4: Simulation curves under the PI method. (a) Speed response and (b) q-axis current response.

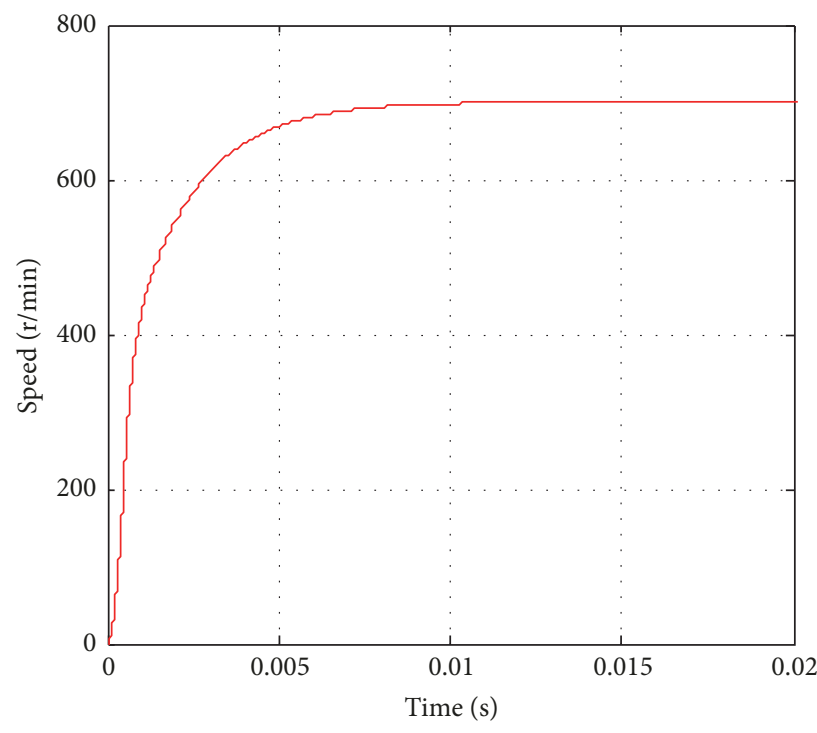

(a)

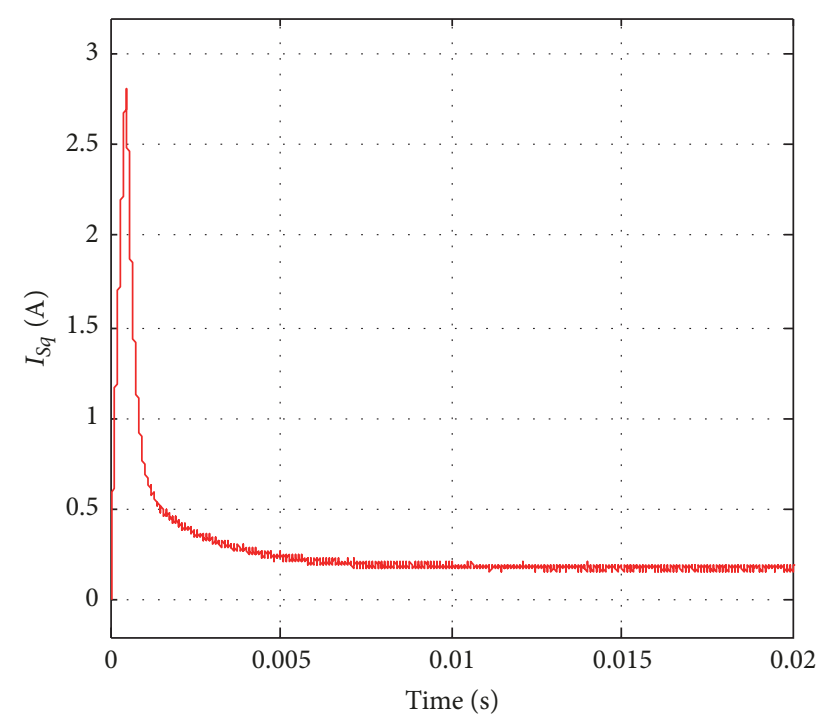

(b)

FIgURE 5: Simulation curves under the ASMC method. (a) Speed response and (b) $q$-axis current response.

effects in the control system [18], for example, chattering and long setting times.

To address the chattering, a variable exponent part [18] is employed in the reaching law, where a time-varying modified factor $\rho|x|$ is introduced to the switching gain. Modified factor is designed as follows

$$
\rho|x|=\frac{|x|}{|x|+\sigma},
$$

where $\sigma$ is the modified factor.

Considering the long setting time, a power part [17] is applied to the reaching law, which can improve the system speed when the state is far from the sliding mode and reduce the chattering when the system state arrives at the sliding band. The dynamic factor is formulated as follows:

$$
\dot{s}=-k|s|^{\alpha} \operatorname{sgn}(s),
$$

where $k>0,1<\alpha<2$.

The reaching law with respect to the speed tracking error can thus be expressed as

$$
\dot{s}=-g \operatorname{sgn}(s)=-\left(k_{2} \rho\left(e_{\omega}\right)+k_{3}|s|^{\alpha}\right) \operatorname{sgn}(s),
$$

where $k_{2}$ is the switching gain of the sliding-mode surface and $k_{3}$ is the power coefficient of the sliding-mode surface. 


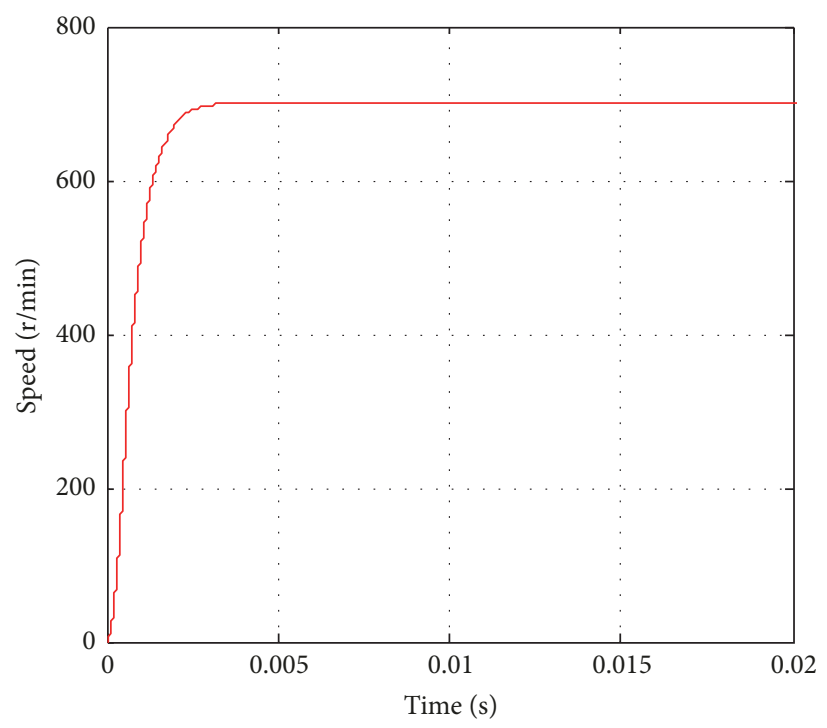

(a)

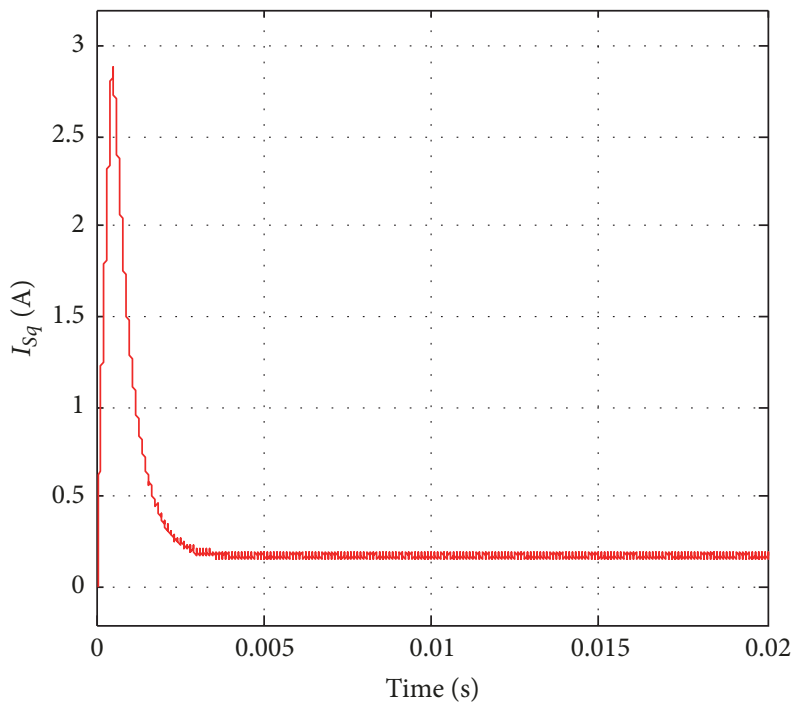

(b)

Figure 6: Simulation curves under the ASMC + ESO method. (a) Speed response and (b) $q$-axis current response.

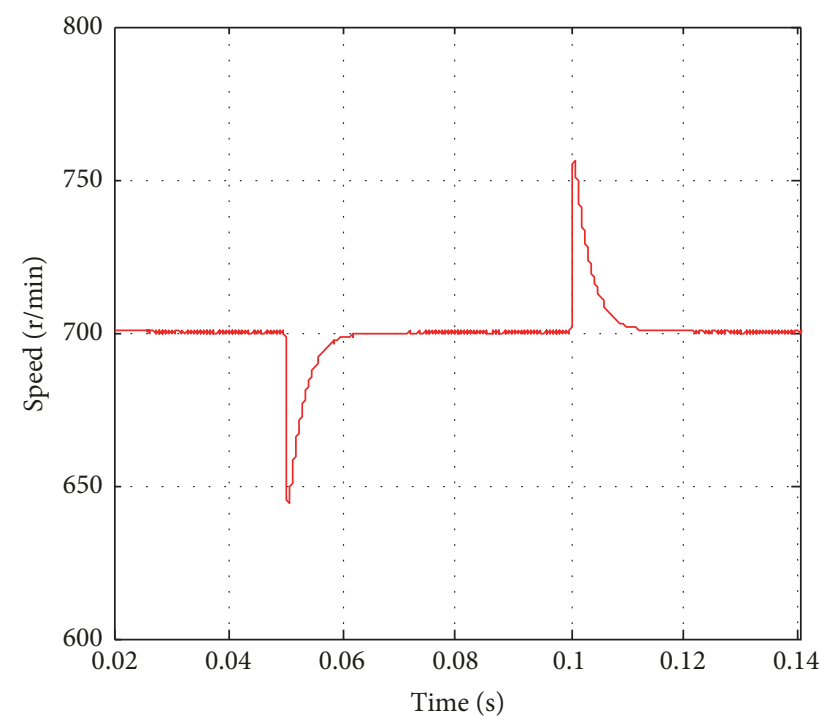

(a)

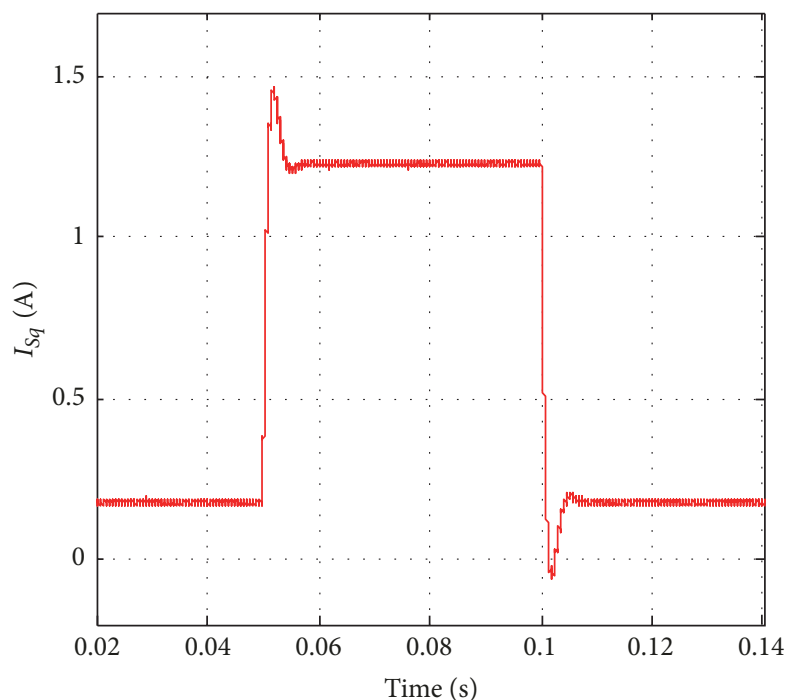

(b)

FIGURE 7: Simulation curves under the PI method. (a) Speed when a sudden load is added or removed and (b) $q$-axis current when sudden load is added or removed.

Therefore, the modified switching gain $k_{2} \rho\left(e_{\omega}\right)$ is always smaller than the original $k_{2}$, reducing the system chattering upon arrival of the sliding band. It decays to zero with the system state to overcome the disadvantages of the regular exponent reaching law.

(D) Sliding-Mode Control Law. With $D$ as the disturbance term, a speed SMC law based on the proposed reaching law can be derived from (9), (12), and (17) as follows:

$$
i_{q}=\frac{1}{K_{t} / J}\left(\dot{\omega}^{*}+\left(k_{1}-\frac{B}{J}\right) e_{\omega}+g \operatorname{sgn}(s)\right)
$$

where

$$
g>\left(a_{1}|\omega|+b_{1}\left|i_{q}\right|+c_{1}\left|T_{l}\right|+d_{1}+|D|\right) .
$$

Theorem 1. Consider the uncertain system (9). Given the sliding-surface function (12) and the control law (18), and (19), the sliding mode is reached in finite time. The tracking error declines asymptotically.

$\left(D^{*}\right)$ Adaptive Sliding-Mode Control Law. It is well known that the parameter variations, $\Delta a, \Delta b, \Delta c$ and $\varepsilon$, usually exist in a practical PMSM. However, the upper bounds of uncertainties 


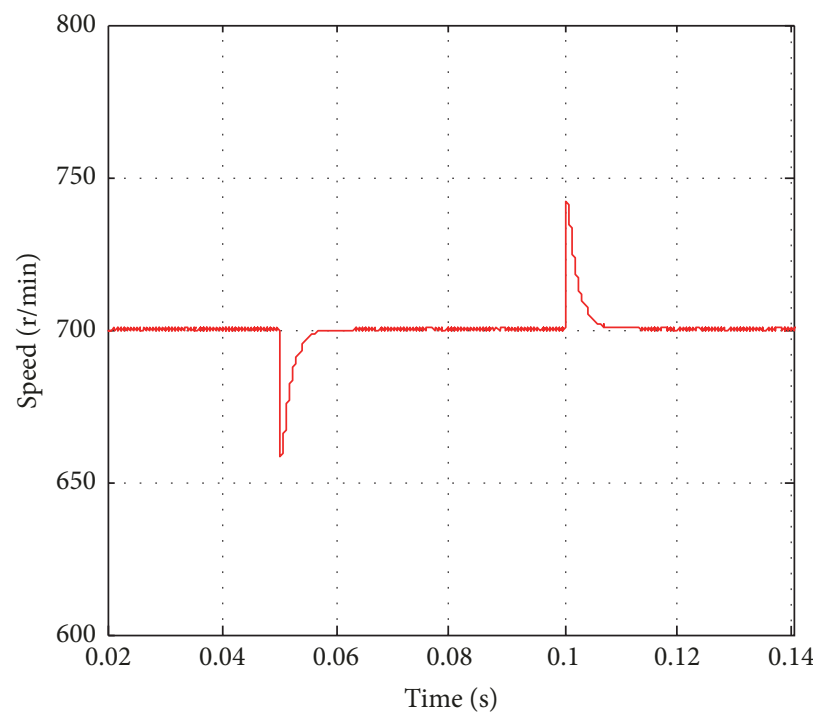

(a)

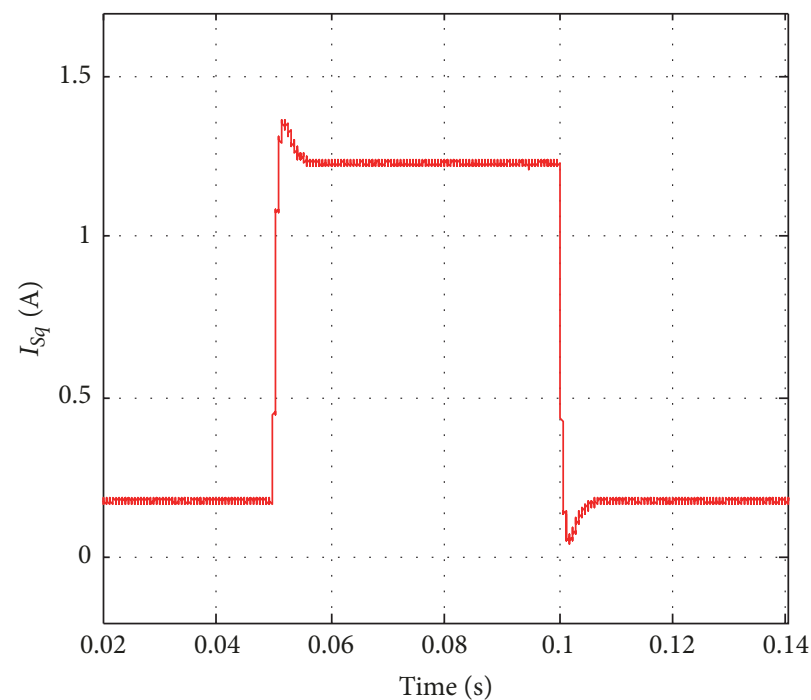

(b)

FIGURE 8: Simulation curves under the ASMC method. (a) Speed when a sudden load is added or removed and (b) q-axis current when a sudden load is added or removed.

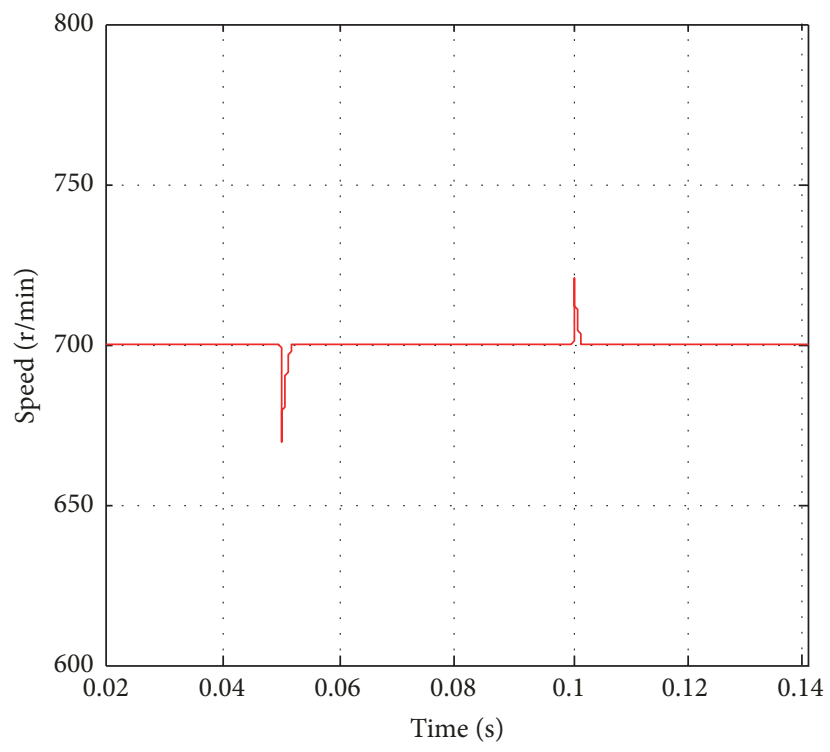

(a)

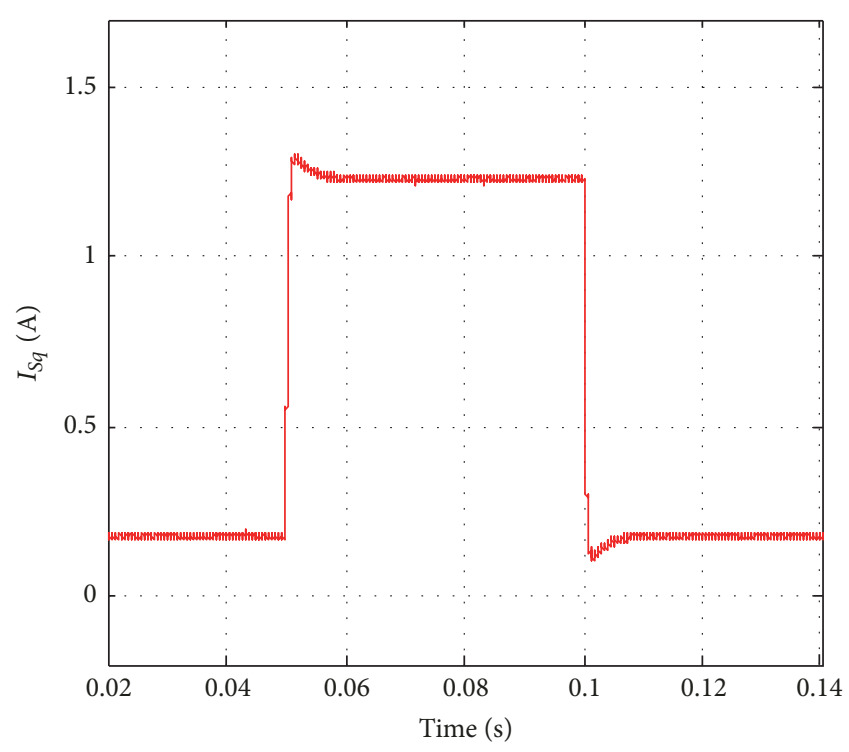

(b)

FIGURE 9: Simulation curves under the ASMC + ESO method. (a) Speed when a sudden load is added or removed and (b) $q$-axis current when a sudden load is added or removed.

TABLE 2: Comparisons of disturbance rejection performance.

\begin{tabular}{|c|c|c|c|}
\hline Control method & PI & ASMC & $\mathrm{ASMC}+\mathrm{ESO}$ \\
\hline Speed fluctuation at loading $(\mathrm{r} / \mathrm{min})$ & 56 & 41 & 29 \\
\hline Speed fluctuation at unloading & 56 & 41 & 21 \\
\hline Speed adjustment time at loading (s) & 0.02 & 0.01 & 0.003 \\
\hline Speed adjustment time at unloading & 0.02 & 0.01 & 0.002 \\
\hline Overshoot in $I_{q}$ at loading (A) & 0.245 & 0.135 & 0.07 \\
\hline Overshoot in $I_{q}$ at unloading & 0.23 & 0.14 & 0.07 \\
\hline$I_{q}$ adjustment time at loading $(\mathrm{s})$ & 0.007 & 0.007 & 0.006 \\
\hline$I_{q}$ adjustment time at unloading & 0.01 & 0.008 & 0.007 \\
\hline
\end{tabular}




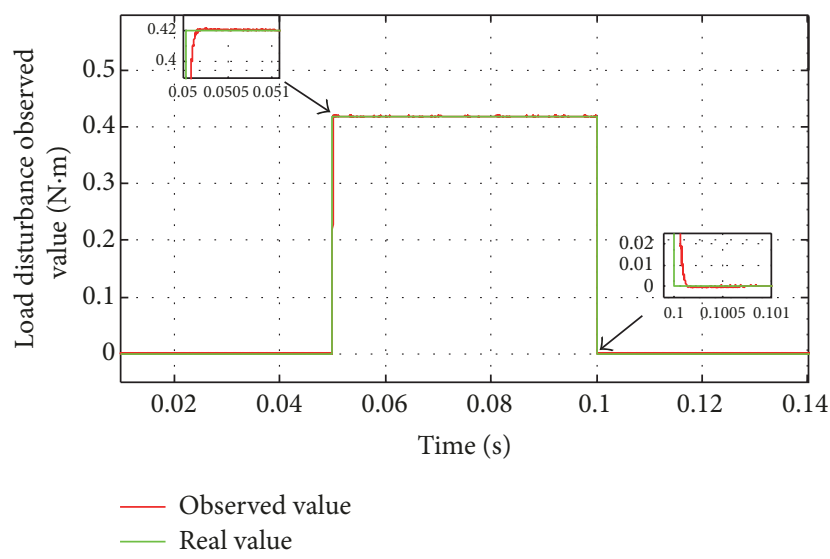

FIGURE 10: Estimated load disturbance of the ESO (simulation).

$a_{1}, b_{1}, c_{1}$ and $d_{1}$ are difficult to be known. In other words, $g$ in SMC is usually chosen to be large positive values to ensure the system stability. It is unavoidable that the large control gain leads to high-frequency chattering, which substantially reduces system performance. In order to avoid using big switching gain in the whole control process and to obtain high-precision control performance, cancelling the effect of system uncertainties by online estimating the real system uncertainties is necessary. Thus, an SMC algorithm with uncertainties estimation for a PMSM is proposed and illustrated as follows :

$$
i_{q}^{*}=\frac{1}{K_{t} / J}\left(\dot{\omega}^{*}+\left(k_{1}-\frac{B}{J}\right) e_{\omega}+\widehat{f}+g^{*} \operatorname{sgn}(s)\right),
$$

where $\widehat{f}$ is the estimated value of $f$ and $g^{*}$ is a positive constant. Define the estimation law as

$$
\dot{\hat{f}}=\beta s,
$$

where $\beta>0$ is the estimation gain.

Theorem 2. Consider the uncertain system (9). Given the sliding-surface function (12), the control law (20), and the estimation law (21), then (9) will be stabled. System robustness is guaranteed and system uncertainty is estimated eventually.

(E) Continuous Switching Function. Since control force $i_{q}^{*}$ gives rise to chattering because of the sign function $\operatorname{sgn}(s)$, the direct application of such a control signal to the system may be impractical. To obtain a continuous control signal, the discontinuous sign function in the control law in (20) can be replaced with a proper continuous smoothing function $[18,19]$ as

$$
\operatorname{sgn}_{\delta}(s) \approx \frac{s}{|s|+\delta},
$$

where $\delta$ is a positive constant. However, chattering cannot be alleviate effectively if $\delta$ is too small; otherwise, the dynamic response of the sliding motion will worsen. Thus, under different operating conditions, a proper continuous function with $\delta$ as a constant may not effectively eliminate the chattering phenomenon. To improve the performance, $\delta$ can be chosen alternatively as a function of $e_{\omega}$ as

$$
\delta\left(e_{\omega}\right)=\delta_{0}+\delta_{1}\left|e_{\omega}\right|,
$$

where $\delta_{0}$ and $\delta_{1}$ are positive constants.

Substituting $M_{\delta}(s)$ for $\operatorname{sgn}(s),(20)$ can be rewritten as

$$
i_{q}^{*}=\frac{1}{K_{t} / J}\left(\left(k_{1}-\frac{B}{J}\right) e_{\omega}+\widehat{f}+g^{*} M_{\delta}(s)\right) .
$$

(F) Stability Analysis. By direct computation, take the derivative of (12) with respect to time; then

$$
\begin{aligned}
\dot{s}= & \dot{e}_{\omega}+k_{1} e_{\omega} \\
= & \dot{\omega}^{*}-\frac{B}{J} e_{\omega}-\frac{K_{t}}{J} i_{q}+D \\
& +\left(\Delta a \omega-\Delta b i_{q}+\Delta c T_{l}-\varepsilon\right)+k_{1} e_{\omega} .
\end{aligned}
$$

Substituting (18) into (25) and both side are multiplied by $s$, then

$$
\begin{aligned}
s \dot{s} & =s\left(-g \operatorname{sgn}(s)+D+\left(\Delta a \omega-\Delta b i_{q}+\Delta c T_{l}-\varepsilon\right)\right) \\
& =-g|s|+s\left(D+\left(\Delta a \omega-\Delta b i_{q}+\Delta c T_{l}-\varepsilon\right)\right) \\
& \leq-g|s|+\left(a_{1}|\omega|+b_{1}\left|i_{q}\right|+c_{1}\left|T_{l}\right|+d_{1}+|D|\right)|s| .
\end{aligned}
$$

Denote $\kappa=g-\left(a_{1}|\omega|+b_{1}\left|i_{q}\right|+c_{1}\left|T_{l}\right|+d_{1}+|D|\right)$. Clearly, $\kappa>0$ according to (19). Then (26) can be rewritten as

$$
s \dot{s} \leq-\kappa|s| \leq 0 .
$$

Note that (27) holds for all time even if the system uncertainties exist. Since $g$ is chosen to satisfy (19), (27) implies that the system trajectory will move towards and reach the sliding surface in finite time. The situation of $s \dot{s}=0$ is merely $s=0$. Therefore the control law given by (18) and (19) guarantees that the sliding mode will be reached and sustained thereafter.

$\left(F^{*}\right)$ Stability Analysis. Let the estimation error of system uncertainty be $e_{f}=f-\widehat{f}$ and choose a Lyapunov function candidate as

$$
V=\frac{1}{2} s^{2}+\frac{1}{2} \frac{1}{\beta} e_{f}^{2} .
$$

Assumption 3. The variation of $f$ is nearly zero during each sampling interval, that is, $\dot{f} \approx 0$ [20].

Taking the derivative of $V$ in (28) yields

$$
\begin{aligned}
\dot{V}= & s \dot{s}+\frac{1}{\beta} e_{f} \dot{e}_{f} \\
= & s\left(\dot{\omega}^{*}-\frac{B}{J} e_{\omega}-\frac{K_{t}}{J} i_{q}^{*}+D+f+k_{1} e_{\omega}\right) \\
& +\frac{1}{\beta} e_{f}(-\dot{\vec{f}})
\end{aligned}
$$




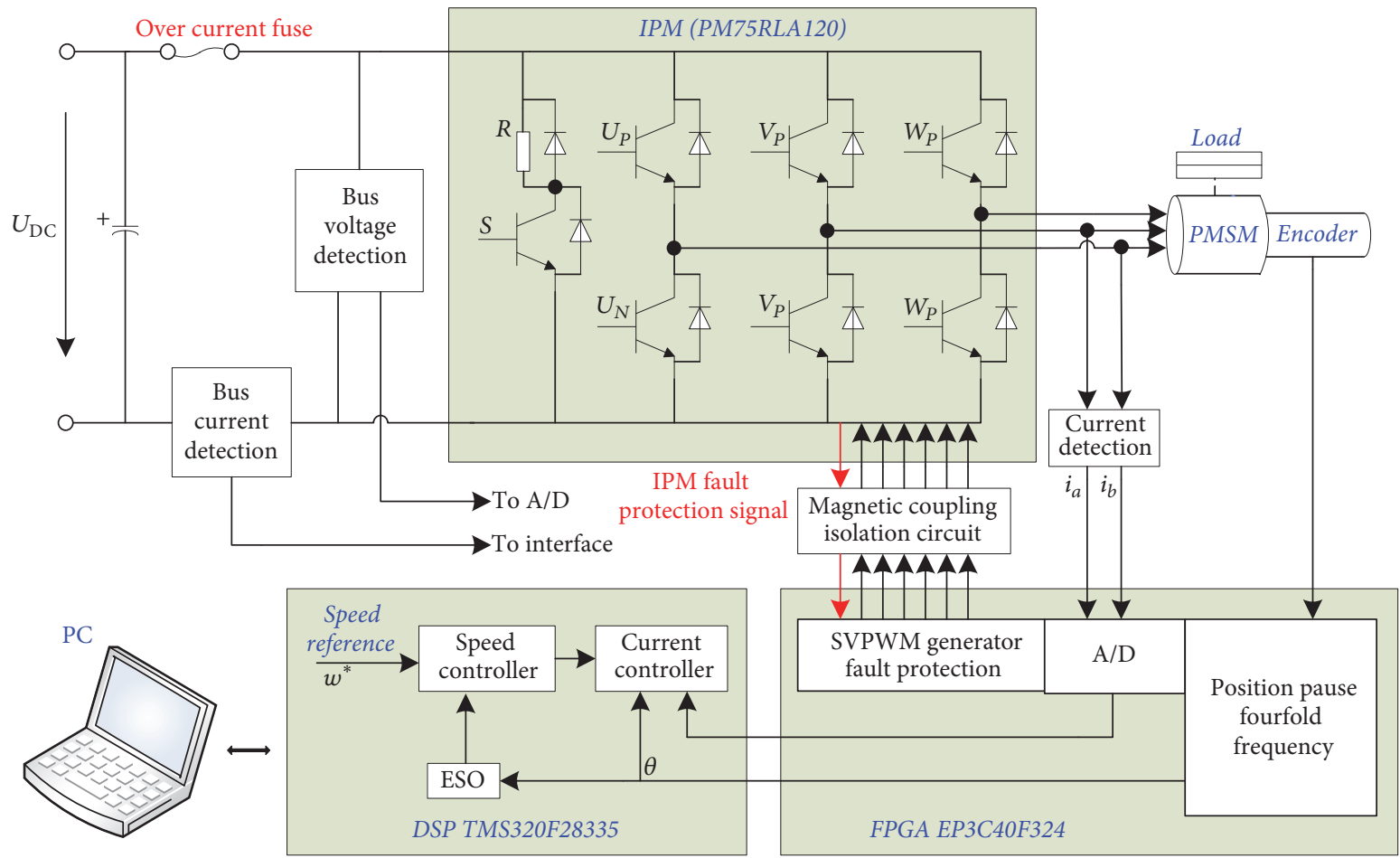

FIgURE 11: Hardware configuration of the PMSM drive and control system.

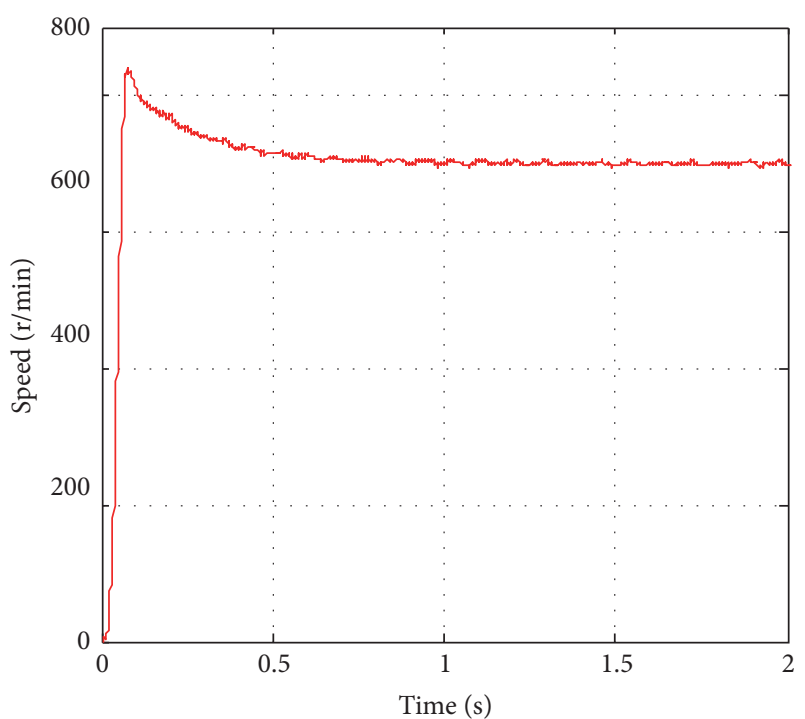

(a)

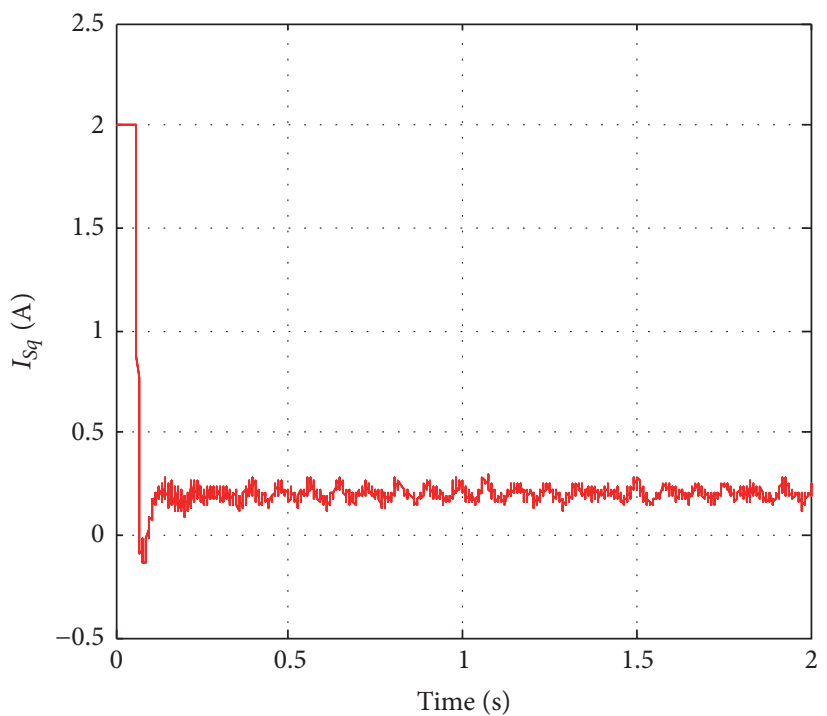

(b)

FIGURE 12: Experimental curves of step response under the PI method. (a) Speed response and (b) q-axis current response.

$$
\begin{aligned}
& =s\left(-\widehat{f}-g^{*} M_{\delta}(s)+D+f\right)-s e_{f} \\
& =s\left(D-g^{*} M_{\delta}(s)\right) \leq 0 .
\end{aligned}
$$

Then, the control gain of $g^{*}$ should be chosen as

$$
g^{*}>|D|
$$

It is obvious that the control law (20) with the estimation law (21), which is applied in the system (9), can hold if $\dot{V} \leq 0$ while $V>0$.

According to the Lyapunov stability theorem, $V$ reaches zero in finite time. That is, $s$ approach zero, and the slidingmode will also be achieved. Finally, the elimination of tracking error $e_{\omega}$ can be guaranteed. In addition, the estimated uncertainties $\widehat{f}$ can be forced forward to the real uncertainties $f$. 


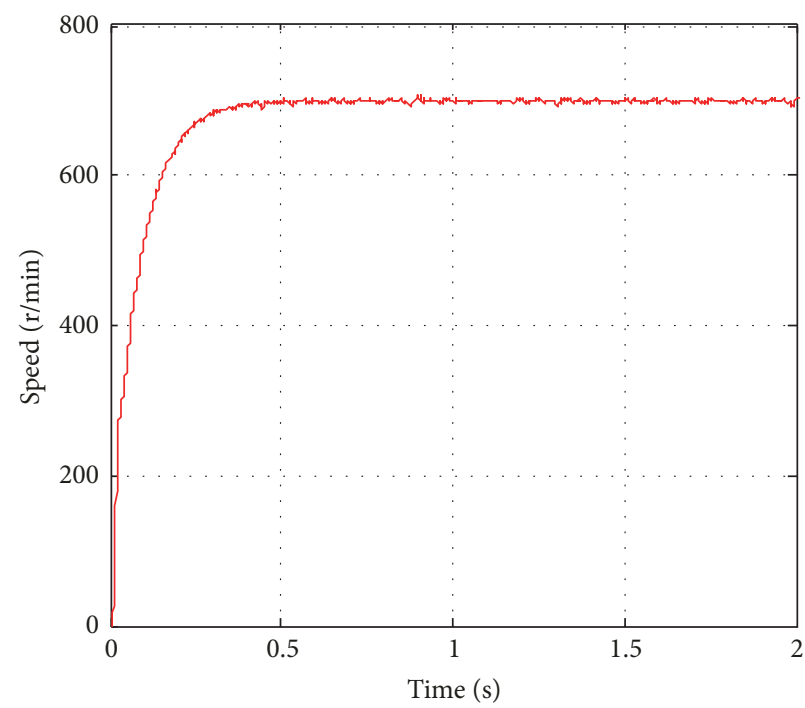

(a)

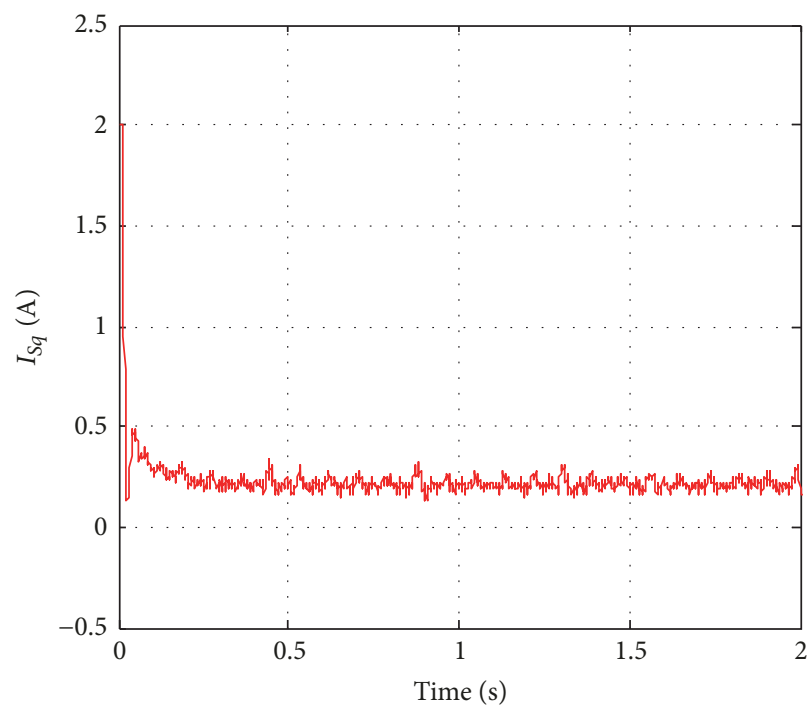

(b)

FIGURE 13: Experimental curves of step response under the ASMC method. (a) Speed response and (b) $q$-axis current response.

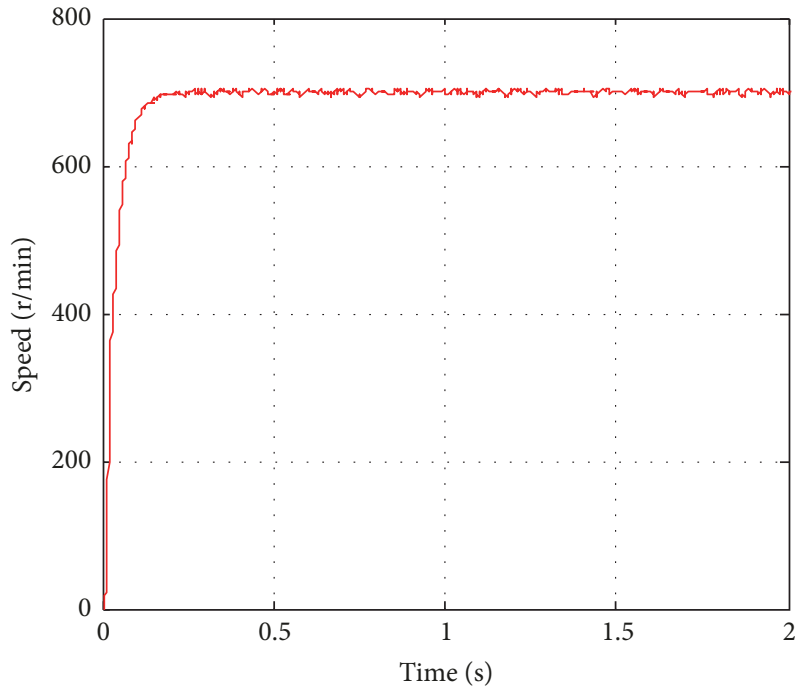

(a)

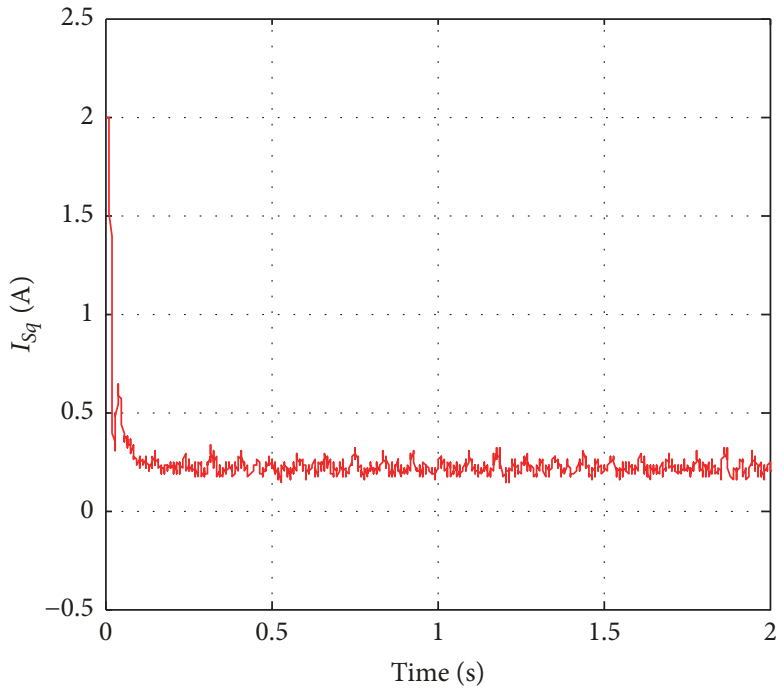

(b)

FIGURE 14: Experimental curves of step response under the ASMC + ESO method. (a) Speed response and (b) $q$-axis current response.

In summary, the ASMC method is not necessary to obtain the upper bounds of uncertainties. Further, the real uncertainty can be estimated and the estimated uncertainty can be used online in the controller to compensate control force and to eliminate the effect caused by the real uncertainty. Thus, the control gain $g^{*}>|D|$ of the ASMC method can be designed much smaller than those $g>\left(a_{1}|\omega|+b_{1}\left|i_{q}\right|+c_{1}\left|T_{l}\right|+d_{1}+|D|\right)$ of the SMC method, to some tent, alleviating system chattering.

\section{ESO Design}

(A) Observer Design. From (30), we can see that the minimum switching gain, which should increase along with the increase in the range of load disturbance can satisfy (29). However, the increase in control gain will increase system chattering. If we introduce a corresponding feed-forward compensation control design to suppress the load disturbance, a small control gain can meet the sliding-mode existence and accessibility condition and thus alleviate system chattering.

The dynamic equation can be described from (9) as

$$
\dot{\omega}=\frac{B}{J}\left(\omega^{*}-\omega\right)+\frac{K_{t}}{J} i_{q}-D-f .
$$

Given (31) and $f \approx \widehat{f}$, we can obtain

$$
\dot{\omega}=a(t)+b_{0} i_{q}^{*}-\widehat{f},
$$



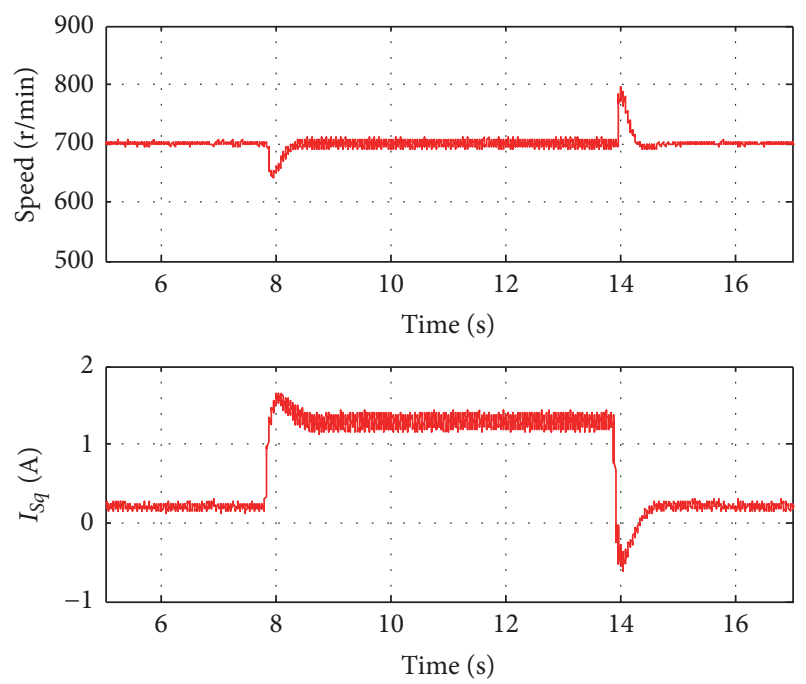

FIGURE 15: Experimental curves when a sudden load is added or removed under the PI method: Speed response and $q$-axis current response.
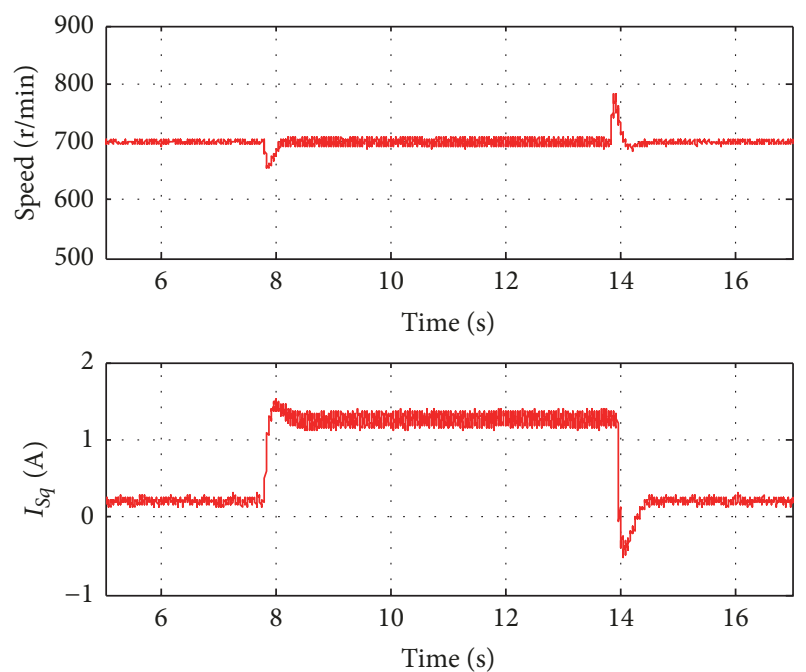

FIGURE 16: Experimental curves when a sudden load is added or removed under the ASMC method: speed response and $q$-axis current response.

where $a(t)=(B / J)\left(\omega^{*}-\omega\right)-D+\left(K_{t} / J\right)\left(i_{q}-i_{q}^{*}\right)+\left(K_{t} / J-b_{0}\right) i_{q}^{*}$ represent $s$ the lumped disturbances, including the friction, the external load disturbances, and the tracking error of the current loop of $i_{q}$. Note that $b_{0}=K_{t} / J$.

With $\omega$ as the state variable and $a(t)$ as an extended state, we define
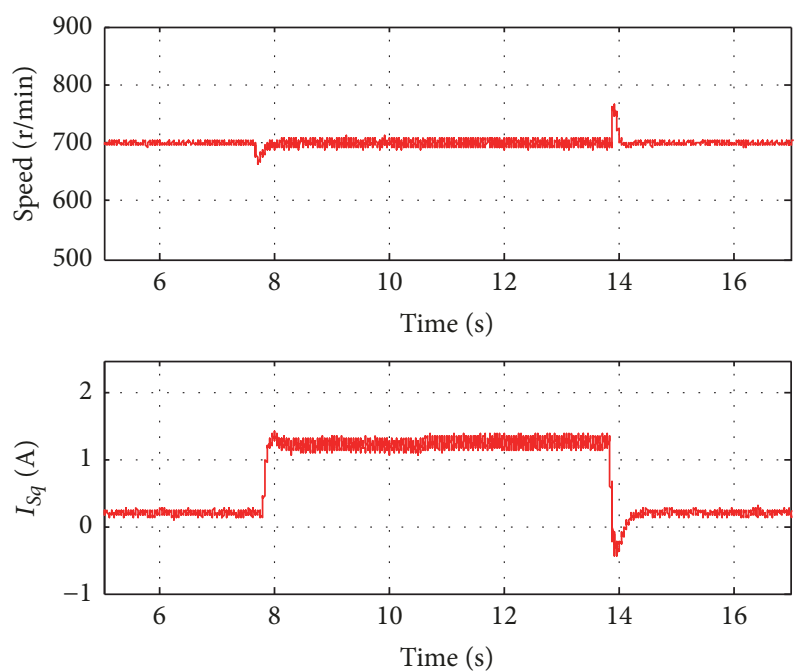

FIgURE 17: Experimental curves when a sudden load is added or removed under the ASMC + ESO method: Speed response and $q$ axis current response.

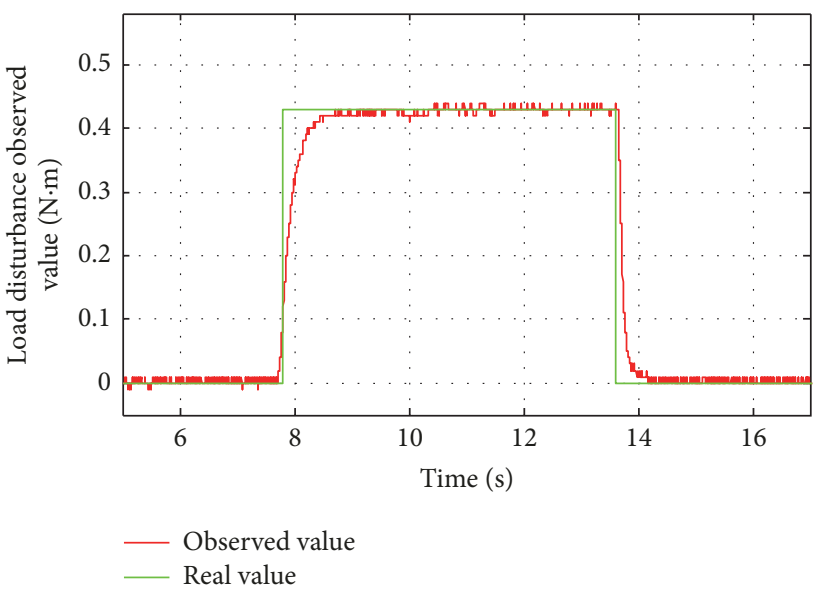

FIGURE 18: Estimated load disturbance of the ESO (experiment).

Then, the dynamics of system (32) can be rearranged into the following state equation:

$$
\begin{aligned}
& \dot{x}_{1}=x_{2}+b_{0} i_{q}^{*}-\widehat{f}, \\
& \dot{x}_{2}=a a(t), \\
& y=x_{1},
\end{aligned}
$$

where $a a(t)=\dot{a}(t)$. According to [21], a linear ESO can be constructed for the extended system of (33) as follows:

$$
\begin{aligned}
e & =z_{1}-y, \\
\dot{z}_{1} & =z_{2}-L_{1} e-\widehat{f}+b_{0} i_{q}^{*}, \\
\dot{z}_{2} & =-L_{2} e
\end{aligned}
$$

where $L_{1}=2 \omega_{0}, L_{2}=\omega_{0}^{2},-\omega_{0}$ describe desired double pole of the ESO, with $\omega_{0}>0$. 
TABLE 3: Comparisons of disturbance rejection performances.

\begin{tabular}{lccc}
\hline Control method & PI & ASMC & ASMC + ESO \\
\hline Speed fluctuation at loading (r/min) & 59 & 45 & 38 \\
Speed fluctuation at unloading & 97 & 07 & 67 \\
Speed adjustment time at loading (s) & 0.56 & 0.44 & 0.28 \\
Speed adjustment time at unloading & 0.71 & 0.28 & 0.23 \\
Overshoot in $I_{q}$ at loading (A) & 0.37 & 0.72 & 0.19 \\
Overshoot in $I_{q}$ at unloading & 0.81 & 0.65 & 0.59 \\
$I_{q}$ adjustment time at loading (s) & 0.7 & 0.57 & 0.34 \\
$I_{q}$ adjustment time at unloading & 0.7 & 0.49 \\
\hline
\end{tabular}

Once the observer in (35) is well tuned, its outputs $z_{1}(t)$ and $z_{2}(t)$ in the system of (35) can estimate the state variables $x_{1}(t)$ and the extended state of $x_{2}(t)$ in the system of (34) with high precision.

The block diagram of the ESO-based speed controller for the PMSM is shown in Figure 1. The output $z_{1}(t)$ of ESO will track $\omega(t)$ and can be used as speed feedback to the ASMC. The output $z_{2}(t)$ of the ESO can estimate lumped disturbances and compensate to the output of the ASMC.

(B) Control Law. ESO's observed value $z_{2}$ equivalently compensates the output of the speed ASMC to reduce control gain in the control law in (20). Thus, we can obtain the speed ASMClaw with load disturbance feed-forward compensation as follows:

$$
\begin{aligned}
& i_{q}^{* \prime} \\
& =\frac{1}{K_{t} / J}\left(\dot{\omega}^{*}+\left(k_{1}-\frac{B}{J}\right) e_{\omega}+\widehat{f}+g^{* \prime} M_{\delta}(s)+z_{2}\right) .
\end{aligned}
$$

The term $-\left(K_{t} / J\right)^{-1} z_{2}$ is compensated for by item $(1 / J) T_{l}+(B / J) \omega^{*}$ in (11).

(C) Stability Analysis. Similarly, according to the Lyapunov stability theory, the stability condition of the speed ASMC can be deduced as follows:

$$
\begin{aligned}
\dot{V}= & s \dot{s}+\frac{1}{\beta} e_{f} \dot{e}_{f} \\
= & s\left(\dot{\omega}^{*}-\frac{B}{J} e_{\omega}-\frac{K_{t}}{J} i_{q}^{* \prime}+D+f+k_{1} e_{\omega}\right) \\
& +\frac{1}{\beta} e_{f}(-\dot{\hat{f}}) .
\end{aligned}
$$

Substituting (36) into (37), then

$$
\dot{V}=s\left(D-z_{2}-g^{* \prime} M_{\delta}(s)\right) \leq 0 .
$$

Then, the control gain of $g^{* \prime}$ should be chosen as

$$
g^{* \prime}>\left|D-z_{2}\right| .
$$

Comparing (19), (30), and (39), it is clear that to ensure system stability and robustness, the control gains of the SMC, ASMC, and ASMC + ESO approaches must be designed such that $g>\left(a_{1}|\omega|+b_{1}\left|i_{q}\right|+c_{1}\left|T_{l}\right|+d_{1}+|D|\right), g^{*}>|D|$, and $g^{* \prime}>\left|D-z_{2}\right|$, respectively. Since the load disturbance has been precisely estimated by the ESO, the magnitude of the estimation error $\left|D-z_{2}\right|$, which is expected to converge to zero, can be kept much smaller than the magnitude of the load disturbance $|D|$, similarly, which can be kept smaller than the magnitude of $g>\left(a_{1}|\omega|+b_{1}\left|i_{q}\right|+c_{1}\left|T_{l}\right|+d_{1}+|D|\right)$, To this end, the control gain of the ASMC + ESO method can be designed much smaller than those of the SMC and ASMC methods and thus effectively alleviates system chattering while assuring system robustness.

\section{Simulation and Experiment Results}

To obtain comparative results for the proposed control algorithm, the PI, SMC, ASMC, and ASMC + ESO controller should be employed in simulations and experiments. However, based on the same values of control gain, which can guaranteed satisfied performance of robust speed control by using the ASMC controller; which is not large enough to overcome the system uncertainties by using SMC without uncertainties estimation, this situation may cause a divergent sliding function. For this reason, the SMC without uncertainties estimation may not be implemented since hardware cannot admit a divergent sliding function. Thus, to evaluate the effectiveness of the proposed method, simulations and experiments for the PI, ASMC, and ASMC + ESO methods were carried out. The system used in this study is a 60CB020C PMSM and the specifications of the motor are shown in Table 1. Simulation was performed on the MATLAB/Simulink platform. The experimental platform was constructed using DSP TMS320F28335 and FPGA EP3C40F324 processors. Figure 2 shows the overall block diagram of the ESO-based ASMC speed controller for the PMSM servo system. Figure 3 shows a photograph of the experimental platform.

(A) Simulation Settings. The PI simulation parameters of both current loops are the same: proportional gain $k_{p c}=4$ and integral gain $k_{i c}=0.038$.

The PI simulation parameters of the speed loop use proportional gain $k_{p v}=0.013$ and integral gain $k_{i v}=0.0016$. The simulation parameters of the ASMC speed loop are $k_{1}=$ 6.8, $k_{2}=483, k_{3}=127, \alpha=1.6, \sigma=2, \delta_{0}=15$, $\delta_{1}=100$, and $\beta=0.0003$. The simulation parameters of the 
ASMC + ESO speed loop are $k_{1}=6.8, k_{2}=483, k_{3}=127$, $\alpha=1.6, \sigma=2, \delta_{0}=15, \delta_{1}=100, \beta=0.0003$, and $-\omega_{0}=-150$.

(B) Simulation Results. Figures 4-6 show the simulation curves of the speed response and $q$-axis current response under a speed command of $700 \mathrm{r} / \mathrm{min}$. The simulation results clearly show that, compared with the speed response of the PI method (17.1\% overshoot and $0.014 \mathrm{~s}$ adjustment time), the speed response under the ASMC method has a much smaller overshoot $(0 \%)$ and a shorter adjustment time (0.01 s). Moreover, the better feed-forward compensation effect of the ESO gives the PMSM speed regulation system the best dynamic performance ( $0 \%$ overshoot and $0.004 \mathrm{~s}$ adjustment time). Meanwhile, the $q$-axis current responds the quickest and has the smallest overshoot compared with that of the PI and ASMC methods.

Figures 7-9 show the simulation curves of the speed response and $q$-axis current response when a sudden load is added or removed. Where the load disturbance $T_{l}=$ $0.42 \mathrm{~N} \cdot \mathrm{m}$ is added abruptly and removed after a time duration of $t=0.05 \mathrm{~s}$. The simulation results with respect to these methods are shown in Table 2. The results show that the ASMC + ESO method has the least speed fluctuations and $q$-axis current fluctuations. Further, the settling time needed for the speed and $q$-axis current to return to the original value is the smallest. This demonstrates that the ASMC + ESO method can obtain better system dynamic performance and robustness to disturbances than the PI and ASMC methods. The estimated load disturbance of the ESO and load disturbance command are shown in Figure 10.

(C) Experiment Description. Step response and load disturbance experiments were performed for the proposed method to validate the reduction in chattering and robustness to disturbances of the speed controller. The hardware configuration of the PMSM drive and control system is shown in Figure 11. The overall control schematic was built based on the DSP TMS320F283355 and FPGA EP3C40F324. An incremental optical encoder was utilized to measure the digital position and the resolution ratio is 2,500 pulses per revolution (ppr). A quadruplicate frequency was achieved by adopting a field programmable gate array; thus, the resolution ratio can be increased to $10,000 \mathrm{ppr}$.

The PI parameters of both current loops are the same: proportional gain $k_{p c}=4.8$ and integral gain $k_{i c}=0.03$.

The PI parameters of the speed loop are proportional $k_{p v}=0.016$ and integral gain $k_{i v}=0.002$. The parameters of the ASMC speed loop are $k_{1}=8, k_{2}=425, k_{3}=120$, $\alpha=1.5, \quad \sigma=2, \delta_{0}=13, \delta_{1}=85$, and $\beta=0.0003$. The parameters of the ASMC + ESO speed loop are $k_{1}=8$, $k_{2}=425, k_{3}=120, \alpha=1.5, \sigma=2, \delta_{0}=13, \delta_{1}=85$, $\beta=0.0003$, and $-\omega_{0}=-100$.

(D) Experimental Results. The step responses of the PI, ASMC, and ASMC + ESO methods under a speed command of $700 \mathrm{r} / \mathrm{min}$ are shown in Figures 12-14. Figures 12(a), 13(a), and 14(a) show the startup procedure of the speed response. Figures 12(b), 13(b), and 14(b) show the $q$-axis current $I_{q}$ response. The experimental results clearly show that the ASMC + ESO method achieves a more satisfactory dynamic response than the PI and ASMC methods. The overshoot of the speed response for the PI method is approximately $20 \%$; that for the ASMC and ASMC + ESO methods decreases to approximately zero. The adjustment time for the PI method is approximately $0.9 \mathrm{~s}$, that for the ASMC method decreases to approximately $0.46 \mathrm{~s}$, and that for the ASMC + ESO method decreases further to approximately $0.19 \mathrm{~s}$.

Moreover, loading and unloading experiments were carried out to verify the disturbance robustness of the PI, ASMC, and ASMC + ESO methods under a speed command of $700 \mathrm{r} / \mathrm{min}$. In these test, the load torque $T_{l}=0.42 \mathrm{~N} \cdot \mathrm{m}$ was added abruptly and removed after a time duration of $t=6 \mathrm{~s}$. The load disturbance was realized by a magnetic power brake. Figures 15-17 shows the dynamic response of the speed and $q$-axis current response. From the experimental curves, it is evident that the proposed method has a more satisfactory robustness to disturbances and exhibits less chattering than those of the PI and ASMC methods. The speed and $q$-axis current of the ASMC method respond more quickly and have a smaller overshoot than the PI method, whereas those for the ASMC + ESO method respond the quickest and have the smallest overshoot. The details of these experimental results are listed in Table 3, which demonstrate that the proposed speed controller enhances the system performance in the presence of load disturbance and alleviates system chattering significantly. Finally, the estimated load disturbance of the ESO is shown in Figure 18, which shows that the ESO can estimate the external load disturbance accurately. The observed value was then used as feed-forward compensation for the speed controller, which improves the dynamic response and robustness of the system.

From these simulation and experiment results, it can be concluded that the ASMC + ESO method enhances the system's dynamic performance and robustness to parameter variations and load disturbance.

\section{Conclusion}

In this paper, a nonlinear SMC algorithm was applied to a PMSM system, to avoid the occurrence of chattering and suppress the effects of disturbances. The major contributions of this study are as follows: (1) an adaptive law was employed to estimate the uncertainty and to compensate for the disturbance of the parameter variations and unmodeled dynamics; (2) an ESO was built to observe the load disturbance, the load disturbance observed value to compensate the output of the speed controller ASMC; and (3) a composite control method that combines ASMC and ESO was designed to further improve the disturbance robustness of ASMC system. Both simulations and experiments were performed to demonstrate the effectiveness and advantages of the proposed method. The results indicate that the proposed method enhances system robustness under system uncertainties and load disturbances, alleviates system chattering effectively, and thus improves system dynamic performance and disturbance robustness compared to the PI and ASMC speed controller. 


\section{Conflicts of Interest}

The authors declare that they have no conflicts of interest.

\section{References}

[1] H.-W. Li, Y.-T. Deng, and J.-L. Wang, "Digital integration of PMSM speed controller based on FPGA," Guangxue Jingmi Gongcheng/Optics and Precision Engineering, vol. 23, no. 4, pp. 1105-1113, 2015.

[2] T. M. Jahns, "Motion Control with Permanent-Magnet AC Machines," Proceedings of the IEEE, vol. 82, no. 8, pp. 1241-1252, 1994.

[3] J. Wang, "Nonlinear PI speed control of permanent magnetic synchronous motor," in Proceedings of the CSEE, vol. 25, pp. 125130, 2005.

[4] S.-K. Kim, K.-G. Lee, and K.-B. Lee, "Singularity-free adaptive speed tracking control for uncertain permanent magnet synchronous motor," IEEE Transactions on Power Electronics, vol. 31, no. 2, pp. 1692-1701, 2016.

[5] S.-K. Kim, "Robust adaptive speed regulator with self-tuning law for surfaced-mounted permanent magnet synchronous motor," Control Engineering Practice, vol. 61, pp. 55-71, 2017.

[6] R. Ramírez-Villalobos, L. T. Aguilar, and L. N. Coria, "Sensorless Ho speed-tracking synthesis for surface-mount permanent magnet synchronous motor," ISA Transactions, vol. 67, pp. 140150, 2017.

[7] R. Jon, Z. Wang, C. Luo, and M. Jong, "Adaptive robust speed control based on recurrent elman neural network for sensorless PMSM servo drives," Neurocomputing, vol. 227, pp. 131-141, 2017.

[8] F. F. M. El-Sousy, "Intelligent mixed $\mathrm{H} 2 / \mathrm{H} \infty$ adaptive tracking control system design using self-organizing recurrent fuzzywavelet-neural-network for uncertain two-axis motion control system," Applied Soft Computing, vol. 41, pp. 22-50, 2016.

[9] J. Yu, P. Shi, W. Dong, B. Chen, and C. Lin, "Neural networkbased adaptive dynamic surface control for permanent magnet synchronous motors," IEEE Transactions on Neural Networks and Learning Systems, vol. 26, no. 3, pp. 640-645, 2015.

[10] T. Tarczewski and L. M. Grzesiak, "Constrained state feedback speed control of pmsm based on model predictive approach," IEEE Transactions on Industrial Electronics, vol. 63, no. 6, pp. 3867-3875, 2016.

[11] Q. Song and J. Chao, "Robust Speed Controller Designed for Permanent Magnet Synchronous Motor Drives Based on Sliding Mode Control," ScienceDirect, vol. 88, pp. 867-873, 2016.

[12] S. Dandan, D. Yugang, and Z. Chengning, "Sliding Mode Controller for Permanent Magnetic Synchronous Motors," in Proceedings of the 8th International Conference on Applied Energy, ICAE 2016, pp. 2641-2646, China, October 2016.

[13] S.-H. Chang, P.-Y. Chen, Y.-H. Ting, and S.-W. Hung, "Robust current control-based sliding mode control with simple uncertainties estimation in permanent magnet synchronous motor drive systems," IET Electric Power Applications, vol. 4, no. 6, pp. 441-450, 2010.

[14] L. C. Xia and J. H. Liu, "Variable structure control of BLDCM based on extended state observer," in CSEE, vol. 26, pp. 139-143.

[15] V. Utkin and J. Shi, "Integral sliding mode in systems operating under uncertainty conditions," in Proceedings of the 35th IEEE Conference on Decision and Control, pp. 4591-4596, Kobe, Japan, December 1996.
[16] Z. Li, D. G. Hu, and R. J. Cui, "Sliding-mode variable structure control with integral action for permanent magnet synchronous motor," in Proceedings of the Proceeding of the CSEE, vol. 34, pp. 431-437, 2014.

[17] J. K. LIU, Sliding Mode Control Design and MATLAB Simulation, Tsinghua University press, Beijing, China, 2012.

[18] N. Jin, X. Wang, and X. Wu, "Current sliding mode control with a load sliding mode observer for permanent magnet synchronous machines," Journal of Power Electronics, vol. 14, no. 1, pp. 105-114, 2014.

[19] T.-L. Chern and Y.-C. Wu, "Design of Integral Variable Structure Controller and Application to Electrohydraulic Velocity Servo systems," in IEE Proceedings-D, vol. 138 (5), pp. 439-444, 1991.

[20] Y. A.-R. I. Mohamed and E. F. El-Saadany, "A current control scheme with an adaptive internal model for torque ripple minimization and robust current regulation in PMSM drive systems," IEEE Transactions on Energy Conversion, vol. 23, no. 1, pp. 92-100, 2008.

[21] Z. Gao, "Scaling and bandwidth-parameterization based controller tuning," in Proceedings of the American Control Conference, pp. 4989-4996, Denver, Colo, USA, June 2003. 


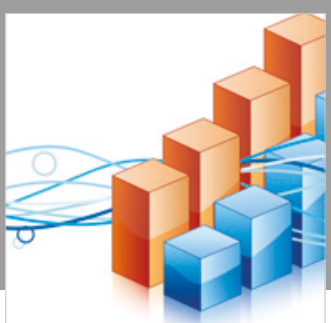

Advances in

Operations Research

\section{-n-m}
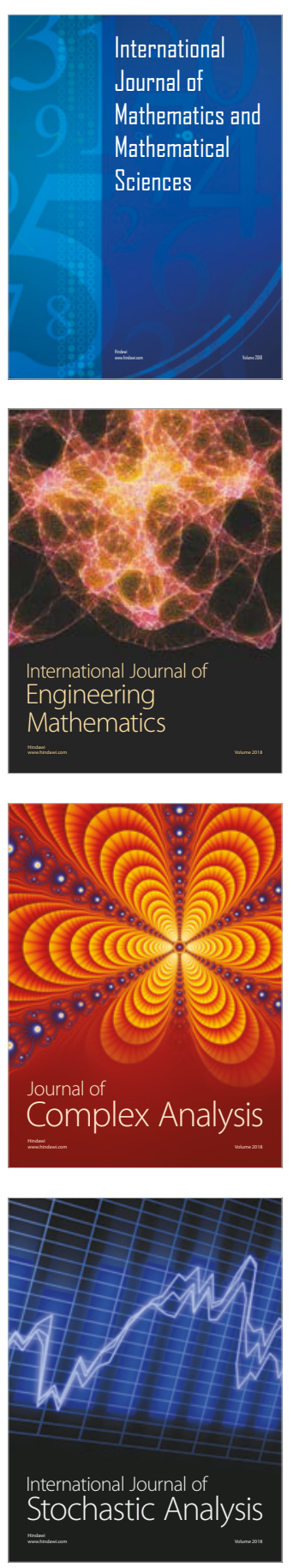
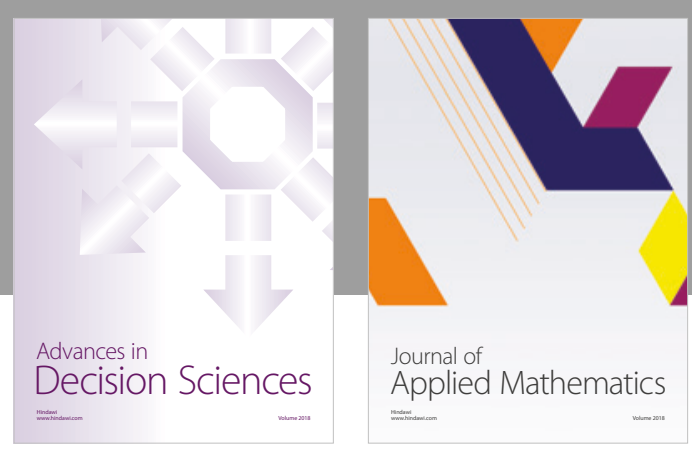

Journal of

Applied Mathematics
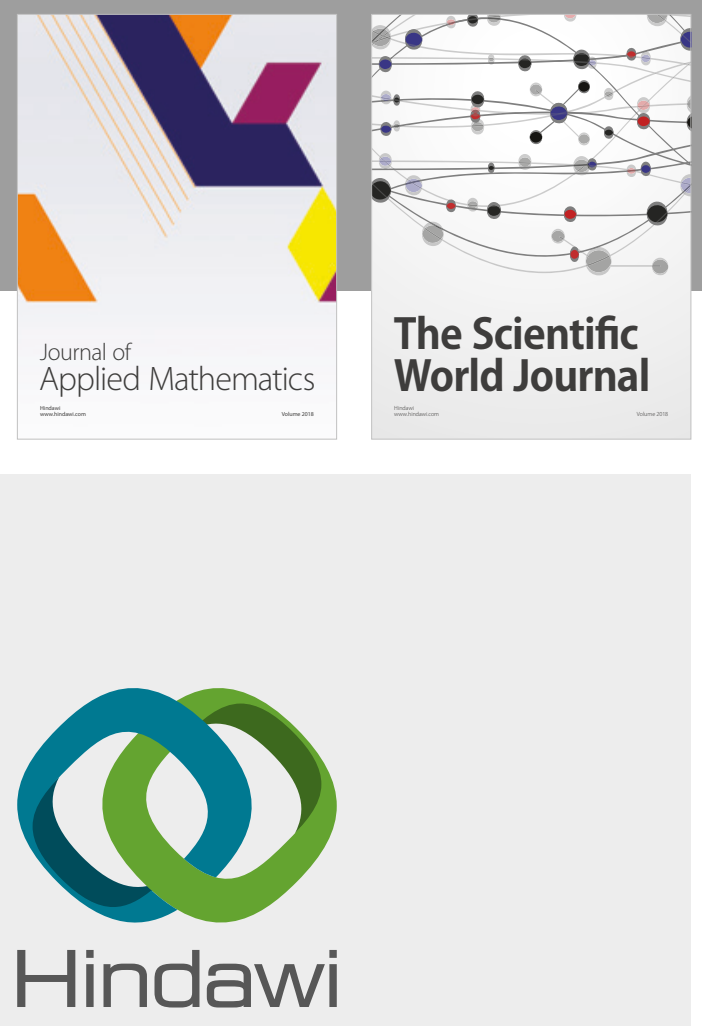

Submit your manuscripts at

www.hindawi.com

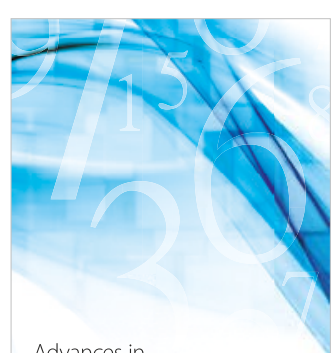

Advances in
Numerical Analysis
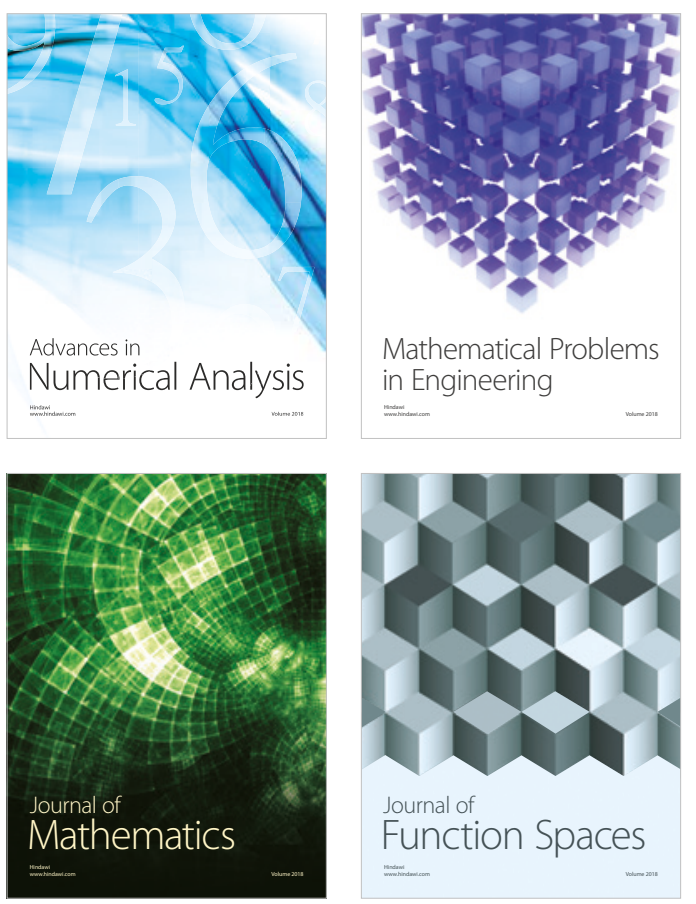

Mathematical Problems in Engineering

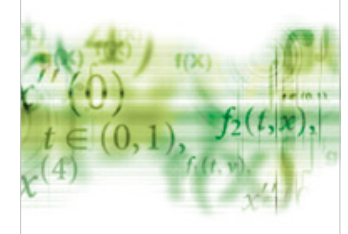

International Journal of

Differential Equations

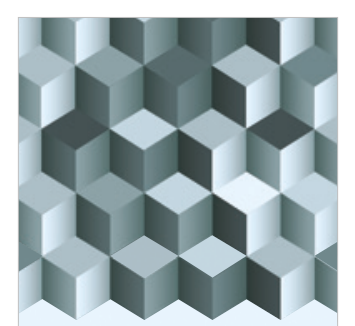

Journal of

Function Spaces

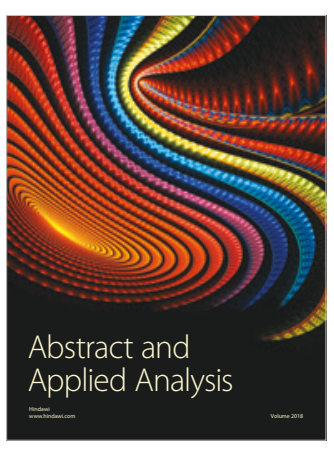

The Scientific

World Journal

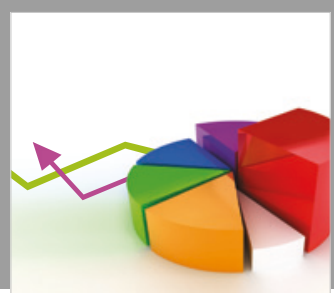

Journal of

Probability and Statistics
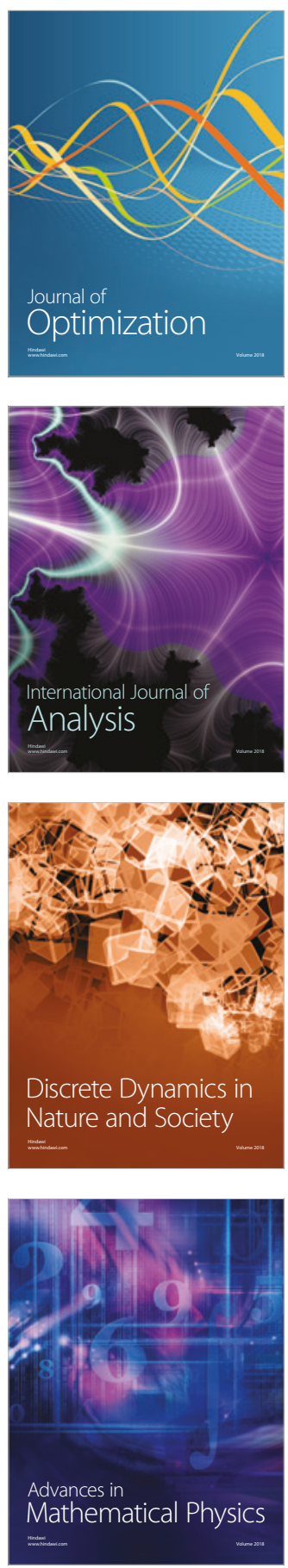